\title{
The Whitening Efficiency on Colored Teeth
}

\author{
Cristina-Stanca Molnar-Varlam, Milena Mkrtchyan, Adrian-Cristian Nicolau, \\ Attila Titus Augustus Szolon
}

University of Medicine and Pharmacy, Tîrgu Mureș, Romania

\section{CORRESPONDENCE}

Attila Titus Augustus Szolon Str. Gheorghe Marinescu nr. 38 540139 Tîrgu Mureș, Romania

Tel +40 746378726

E-mail: dr.szolontitus@yahoo.com

\section{ARTICLE HISTORY}

Received: July 14, 2017

Accepted: August 1, 2017
Cristina-Stanca Molnar-Varlam • Str. Gheorghe Marinescu nr. 38, 540139 Tîrgu Mureș, Romania. Tel: +40265215551

Milena Mkrtchyan - Str. Gheorghe Marinescu nr. 38 , 540139 Tîrgu Mureș, Romania. Tel: +40 265215551

Adrian-Cristian Nicolau • Str. Gheorghe Marinescu nr. 38, 540139 Tîrgu Mureș, Romania. Tel: +40 265 215551
To enhance the natural white color of the teeth, the application of a bleaching agent is used. It is a common technique in cosmetic dentistry, representing one of the most demanded procedures in the dental office. ${ }^{1}$

Dentistry professionals use several bleaching techniques, including bleaching strips, pens, specific gels, and laser tooth-whitening methods. Teeth whitening techniques commonly utilize carbamide peroxide- or hydrogen peroxidebased solutions. ${ }^{2-4}$

Our objective was to assess the change in color following the action of various extrinsic substances (methylene blue-based oral antiseptic, black coffee, CocaCola, black tea, red wine, and blueberry jam) and the teeth's ability to return to their initial shade after bleaching.

We carried out an in vitro study using 34 teeth of various shades identified with the VITA Shade Key (Panels A, D, G, and J). The teeth were immersed into the extrinsic substances for 24 hours (Panels B, E, H, and K). We can notice that every tooth became darker than its initial shade. The last step was to bleach the colored teeth using $14 \%$ hydrogen peroxide for 30 minutes. ${ }^{5,6}$ After application of the whitening agent, the teeth gained a whiter shade, but they could not reach the initial one (Panels C, F, I, and L). The images show that the most spectacular changes occurred while using blueberry jam (Panels A, B, and C), Coca-Cola (Panels D, E, and F), red wine (Panels G, H, and I), and methylene blue-based oral antiseptic (Panels J, K, and L).

We can conclude that Coca-Cola, blueberry jam, red wine, and black tea had the strongest effect. Most teeth had a satisfactory shade after the bleaching, but none of them returned to the initial aspect. The methylene blue-based oral antiseptic turned out to be the least aggressive agent, the final shade being coincident with the initial one (Panels J, K, and L). Aggressive bleaching can lead to deterioration of the tooth by dehydration and demineralization, even if it temporarily looks whiter for a certain period.

\section{CONFLICT OF INTEREST}

Nothing to declare. 

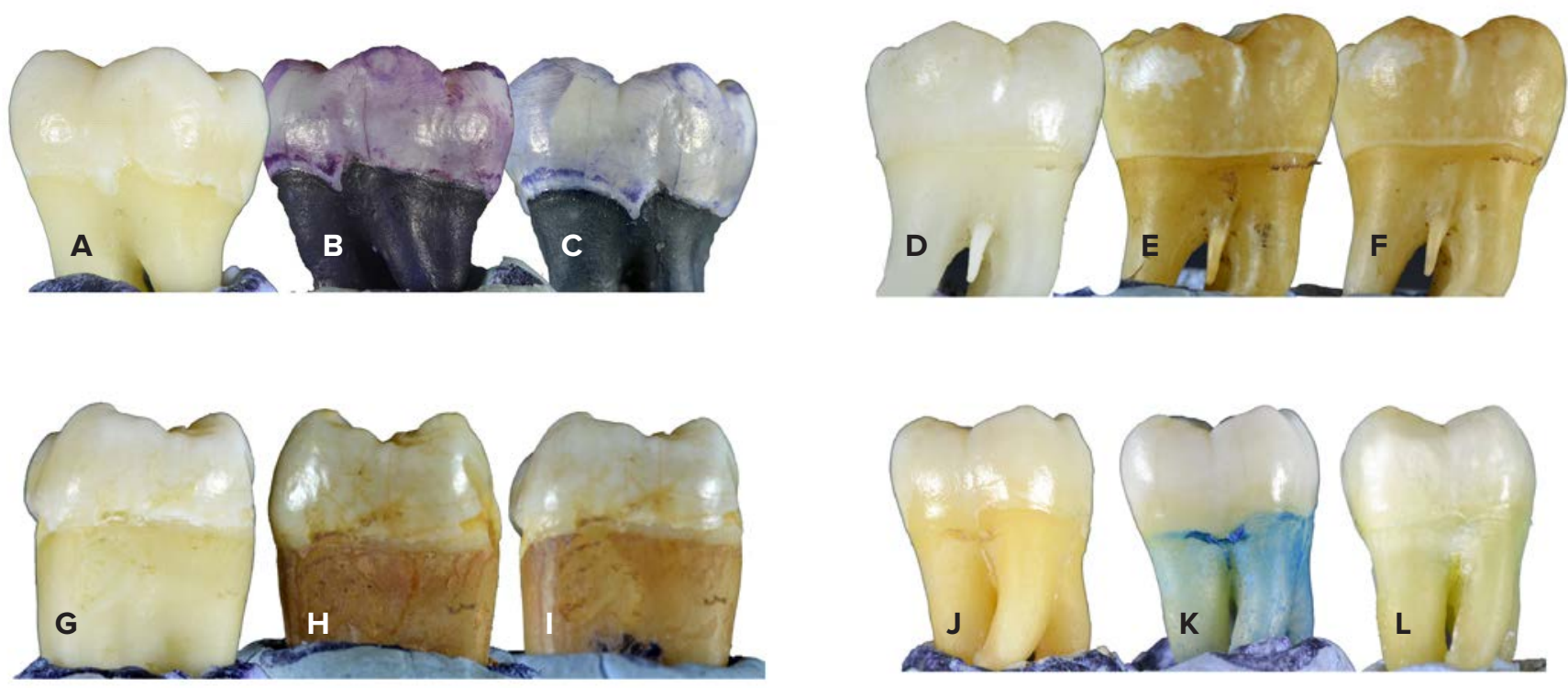

\section{REFERENCES}

1. Carey CM. Tooth Whitening: What We Now Know. J Evid Based Dent Pract. 2014;14:70-76.

2. Myers ML, Browning WD, Downey MC, Hackman ST. Clinical evaluation of a $3 \%$ hydrogen peroxide tooth-whitening gel. J Esthet Restor Dent. 2003;15:50-55

3. Alqahtani Mohammed Q. Tooth-bleaching procedures and their controversial effects: A literature review. The Saudi Dental Journal. 2014;26:33-46.

4. Papathanasiou A, Bardwell D, Kugel G. A clinical study evaluating a new chairside and take-home whitening system. Compend Contin Educ Dent. 2001;22:289-294

5. Li Y, Greenwall L. Safety issues of tooth whitening using peroxide-based materials. Brit Dent J. 2013;215:29-34.

6. Pimenta-Dutra AC, Albuquerque RdeC, Morgan LF. Effect of bleaching agents on enamel surface of bovine teeth: A SEM study. J Clin Exp Dent. 2017;9:46-50 